\title{
Бровко К.А.
}

доктор філософії,

старший викладач кафедри іноземних мов і методик їх навчання,

Київський університет імені Бориса Грінченка,

бульвар Ігоря Шамо, 18/2, 02154, Київ, Україна

k.brovko@kubg.edu.ua

ORCID iD 0000-0001-8572-9316

\section{ФОРМУВАННЯ ІНШОМОВНОÏ МОВЛЕННЄВОЇ ДІЯЛЬНОСТІ ДІТЕЙ 6-7 РОКІВ ЗАСОБОМ WEB-CEPBICY LEARNINGAPPS.ORG}

У статmі розглянуто потенційні можливості та особливості використання Web-сервісу LearningApps.org в формуванні іншомовної мовленнєвої діяльності дітей 6-7 років на заняттях з англійської мови. Здійснено класифікацію видів завдань за функціональною ознакою (Multiplechoice, Sequence або Pairing, Order, Filling in, Group Puzzle, Crossword, Word grid, Patring Game and ect.). Подано їх короткий опис. Проведено стратегічний аналіз Web-сервісу LearningApps.org в формуванні іншомовної мовленнєвої діяльності дітей 6-7 років. Охарактеризовано комплекс методичних, дидактичних, педагогічних і психологічних принципів, який реалізується у прочесі використання Web-сервісів LearningApps.org на заняттях англійської мови.

Окреслено дидактичні можливості формування іншомовної мовленнєвої діяльності дітей 6-7 років на заняттях з англійської мови. Представлено фрагменти власної розробки інтерактивних вправ у Web-сервісі LearningApps.org спрямовані на вивчення лексичних одиниць, граматичних навичок, аудіювання та закріплення вивченого матеріалу з теми «Parts of body. Appearance».

Ключові слова: LearningApps.org; Web-сервіс; англійська мова; діти 6-7 років; іншомовна мовленнєва діяльність.

(c) Бровко К.А., 2021

( ) Київський університет імені Бориса Грінченка, 2021

Вступ. Важливим наслідком цифрової революції став стрімкий розвиток цифровізації, діджиталізації та геймифікації освітнього процесу, що у свою чергу активізує проблему їх активного використання у різноманітних галузях навчання. Сучасний глобалізований світ вже немислимий без широкого застосування сучасних і постійно оновлюючих технологій. Їх розвиток створює основу для реалізації робочих програм з англійської мови на якісно новому рівні, ініціює і розвиває виникнення нових освітніх практик, що, в свою чергу, сприяє трансформації освіти в цілому. Вивчення англійської мови з використанням Web-сервісів підриває успадковану 3 минулого методичну основу навчання «зазубрювання». Цифрові технології надають можливість забезпечити індивідуалізацію освітньої траєкторії, методів і темпу освоєння навчального матеріалу для кожної дитини з використанням нетипових інтерактивних вправ, ігор, аудіо та відео-матеріалів.

Широкий аналіз науково-педагогічних джерел засвідчив, що різноманітні аспекти інтеграції сервісів Web 2.0 в процес формування іншомовної мовленнєвої діяльності були предметом дослі- джень багатьох науковців, як от: Д. Бодненка, К. Бугайчук, К. Корзун, М. Козяр, Н. Морзе, Т. Носенко, С. Паламар, О. Сало, R. Byrne, S. Downes та ін. (дидактичні можливості соціальних сервісів Web 2.0); використання Інтернет-сервісу LearningApps.org в організації освітнього процесу (Б. Білусяк, О. Волкова, Ю. Волобуєва, О. Лущинська, M. Семаньків, G. Gunter, L. Campbell M. Racilan та ін.); застосування цифрових технологій та сервісів Web 2.0 в процесі навчання дошкільників іноземних мов (О. Котенко, Н. Кошарна, О. Мельник, Л. Петрик, О. Тасевіч, А. Соломаха, І. Свірепчук, П. Сафонова, А. Філатова, L. Ferlazzo, J. Picard та ін.);

Мета статті - полягає у теоретичному обгрунтуванні особливостей використання Web-cepвicy LearningApps.org в формуванні іншомовної мовленнєвої діяльності дітей 6-7 років.

Аналіз потенційних можливостей використання Web-cepвicy LearningApps.org в формуванні іншомовної мовленнєвої діяльності дітей 6-7 років.

Використання Web-сервісів на заняттях англійської мови дозволяє більш повно реалізувати цілий комплекс методичних, дидактичних, педа- 
гогічних і психологічних принципів. Це підвищує ефективність вирішення комунікативних завдань, розвиває різні види мовленнєвої діяльності дітей старшого дошкільного віку, формує стійку мотивацію під час занять з англійської мови (Білусяк Б., Семаньків М., 2018, с. 98; Петрик Л., 2019, с. 191).

LearningApps.org $€$ безкоштовним Webсервісом інтерактивних завдань і вправ, які можна розробляти як самостійно, так і використовувати вже розроблений іншими користувачами контент в різних формах організації навчальної і самостійної діяльності на різних етапах занять $з$ англійської мови (закріплення, перевірки та узагальнених набутих знань, умінь та навичок дітей старшого дошкільного віку) (Рuc. 1) (Gunter G., Campbell L., Braga J., Racilan M., V. Souza, 2016; Волубаева В., 2017, с. 40).

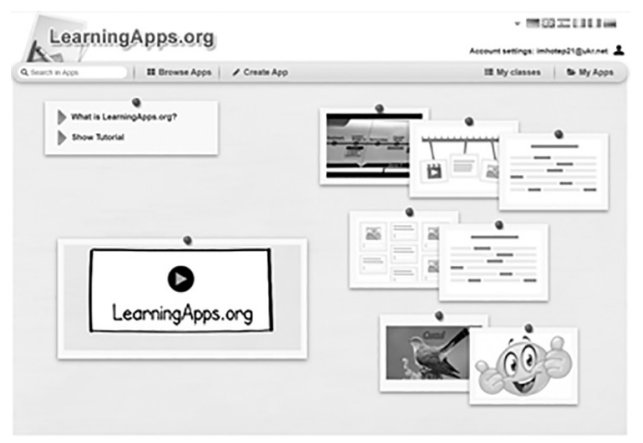

Puc. 1. Загальний вигляд

Web-сторінки LearningApps.org

Ігрова форма завдань допомагає залучити дітей старшого дошкільного віку до процесу навчання, а інтерактивні завдання сервісу надають допомогу і полегшують підготовку навчальних матеріалів для викладача.

Усі завдання веб-сервісу розташовані за категоріями і дозволяють враховувати рівні мовної компетентності дітей старшого дошкільного віку, що є основою для реалізації принципів індивідуалізації та диференційованого підходу в навчанні. Web-cервіс LearningApps. надає можливість отримання QR-коду для того, щоб можна було поділитися посиланням 3 дітьми на інтерактивне завдання у режимі On-line, що особливо актуально за умови дистанційної форми навчання, а також при роботі 3 тією категорією дітей, які пропускають заняття через хворобу або готуються до конкурсів.
Всі представлені завдання згруповані для дітей за функціональною ознакою (Multiple-choice, Sequence або Pairing, Order, Filling in, Group Puzzle, Crossword, Word grid, Patring Game та ін.) (Puc. 2) і вирішують ряд дидактичних завдань: активізує словник дітей, формує навички та вміння читання, удосконалює вміння писемного мовлення дітей, розвиває елементарні мовленнєві навички: аудіювання, говоріння, слугує вправлянню дітей щодо вживання граматичних форм, стимулює дитяче словотворення. Доцільним $є$ також використання сервісу, як ілюстративного засобу, а також засобу оцінки знань, при навчанні аудіювання, а також у проектній діяльності (Мельник О., 2011, с. 17; Solomakha A., Kosharna N., 2020, c. 111).

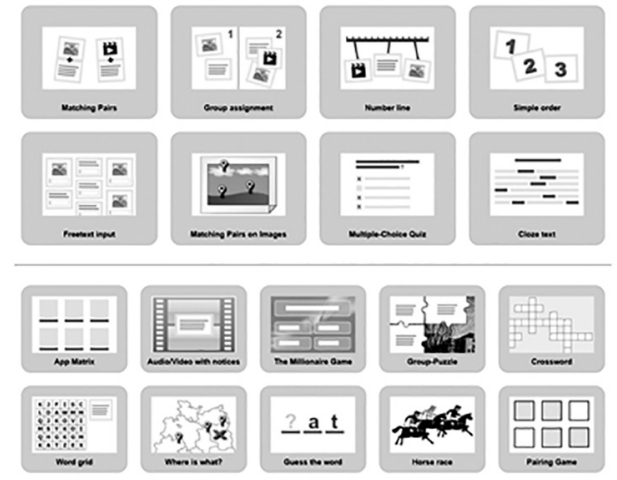

Puc. 2. Перелік доступних шаблонів на сервісі

В рамках першої угруповання завдань дітям пропонуються завдання на вибір правильних відповідей (Multiple-choice), де завдання представлені як у вигляді тексту і картинки, так і у вигляді аудіо- та відеоматеріалів, контенту з іншого вебсторінки у вигляді вбудованого фрейма. Завдання на Pairing (відповідність) представлені у вигляді гри «Парочки», пошуку лексичної пари або граматичних відповідностей. Категорія Order (визначення послідовності) представлена завданнями на розташування по порядку компонентів тексту при виділенні орієнтовної основи дії перекладу пропозицій з української мови на англійську, де дитина навчається виділяти ознаки і вимоги граматичного явища, оперує поняттям «спосіб дії і його послідовність». Категорія Filling in (наповнення) представлена вправами, які необхідно заповнити правильними відповідями: вікторина $з$ введенням тексту, кросворди (Табл. 1) (Learningapps.org, 2021).

\begin{tabular}{|c|c|c|}
\hline \multirow{5}{*}{1.} & \multirow{5}{*}{ Multiple-choice } & $\begin{array}{l}\text { Вікторина - традиційні питання множинного вибору з мультимедійним контентом з декількома } \\
\text { варіантами правильних відповідей }\end{array}$ \\
\hline & & $\begin{array}{l}\text { Вікторина з вибором правильної відповіді - традиційні питання множинного вибору } \\
\text { з мультимедійним контентом з одним правильним варіантом відповіді }\end{array}$ \\
\hline & & Виділення слів - виділення необхідних слів з наданого тексту \\
\hline & & $\begin{array}{l}\text { Гра «Хто хоче стати мільйонером?» - багаторівнева гра (6 рівнів складності), яка містить питання } \\
\text { з чотирма варіантами відповіді }\end{array}$ \\
\hline & & Слова з букв - складання слів з букв які розташовані в одній сітці \\
\hline
\end{tabular}




\begin{tabular}{|l|l|l|}
\hline 2. & Piring & $\begin{array}{l}\text { Сортування картинок, аудіо-, відео-фрагментів - у якості заднього плану використовується } \\
\text { довільне зображення на яке в певних місцях додаються мультимедійні мітки (текст, зображення, } \\
\text { аудіо або відео). } \\
\text { Таблиця відповідностей - кожен елемент (мультиедійний) має дві характеристики, і завдання } \\
\text { користувача - правильно розташувати його в таблиці (на перетині двох характеристик). }\end{array}$ \\
\hline 3. & $\begin{array}{l}\text { Розставити по порядку - за допомогою цього шаблону ви можете розташувати в правильному } \\
\text { порядку тексти, аудіо-, відео-файли } \\
\text { Хронологічна лінійка - за допомогою цього шаблону можна налаштувати шкалу часу (або іншу } \\
\text { шкалу), на якій розташована інформація у вигляді тексту, картинки або відео, аудіо-інформація }\end{array}$ \\
\hline 4. & Filling & $\begin{array}{l}\text { Вікторина з введенням тексту; Заповнити пропуски - завдання з введенням відповіді } \\
\text { на питання }\end{array}$ \\
\hline
\end{tabular}

Стратегічний аналіз Web-cepвicy LearningApps.org в формуванні іншомовної мовленнєвої діяльності дітей 6-7 років.

Охарактеризуємо позитивні якості роботи 3 Web-сервісом LearningApps.org:

1. безкоштовний сервіс зі зрозумілим та доступним у користуванні інтерфейсом на 6 мовах;

2. кожну з розроблених на даному Інтернетресурсі вправ можна використати на своєму занятті, змінити під власні потреби, розробити схожий чи зовсім інший навчальний модуль, його можна зберігати у власному «кабінеті», створивши свій аккаунт;

3. можливість обміну інтерактивними завданнями;

4. завдання можна створювати і редагувати в режимі он-лайн, використовуючи різні шаблони з картинками, звуком та відео;

5. моментальна перевірка правильності виконання завдання;

6. можливість отримати посилання для відправки електронною поштою або QR-код для вбудовування в блог або сайт, розповсюдження в соціальних мережах, взаємообміну в месенджерах;

7. можливості Web-сервісу LearningApps. org дозволяють вчителю зареєструвати на цьому сайті кожну дитину окремо, після чого кожен 3 них заходить в особистий аккаунт за паролем, щоб так чи інакше взаємодіяти в режимі реального часу з учителем та іншими дітьми. Це може бути реалізовано дистанційно або прямо під час заняття;

8. функція завантаження створеної вправи на власний комп'ютер у форматі SCORM, iBook Author, Developer Source.

Серед негативних рис на нашу думку є те, що частина шаблонів не підтримує кирилицю; сервіс залежний від Інтернет-підключення і не може працювати в режимі Offline; в шаблонах зустрічаються окремі помилки, які неможливо виправити вручну; деякі шаблони вправ змінюються або їх вилучають з сайту (Білусяк Б., Семаньків М., 2018, c. 99). Проте, зважаючи на їх доволі неширокий спектр, слід наголосити на вагомих позитивних властивостях у використанні Інтернет-сервісу LearningApps.org в організації навчання дітей 6-7 року життя англійської мови.

У процесі роботи 3 Web-сервісом LearningApps.org в організації навчання старших дошкільників англійської мови, у дітей розвивається критичне та творче мислення; формуються комунікативні навички, зокрема (Kotenko O., Holovatenko T., 2020): аналіз матеріалу, співставлення, порівняння, встановлення асоціацій з відомими фактами, явищами, встановлення асоціацій з новими якостями предметів, явищ тощо; розвивається логіка послідовності дій та вибудовується логіка рішень; розвиваються вміння систематизації та узагальнення матеріалу; навички роботи в колективі в процесі розв'язування завдань.

Розглянемо дидактичні можливості в формуванні іншомовної мовленнєвої діяльності дітей 6-7 року життя на прикладі розроблених нами завдань у Web-сервісі LearningApps.org спрямованих на вивчення лексичних одиниць, граматичних навичок, аудіювання та закріплення вивченого матіералу 3 теми «Parts of body. Appearance».

Приклади інтерактивних вправ 3 англійської мови у Web-сервісі LearningApps.org для формування іншомовної мовленнєвої діяльності дітей 6-7 років. Для того, щоб формувати лексичні навички, в рамках первинної презентації слова слід запропонувати дітям завдання типу вікторини на вибір правильних відповідей (Multiple-choice) (Puc. 3).

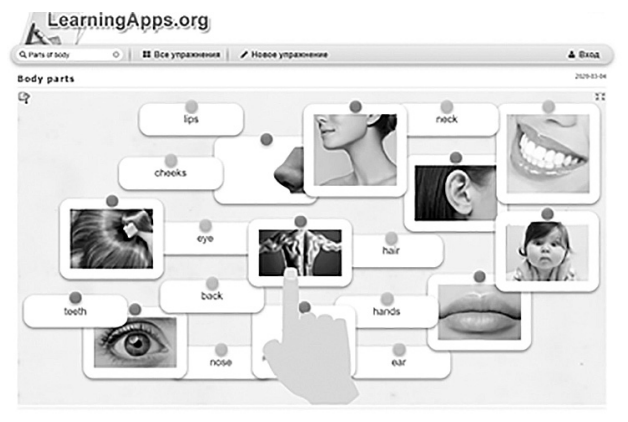

Рuc. 3. Фрагмент завдання з формування лексичної компетентності 
При формуванні граматичних навичок в рамках теми «Parts of body. Appearance» і автоматизації способу дії з переведення пропозицій 3 української мови на англійську актуальними будуть завдання на вибір правильної відповіді (Рuc. 4).

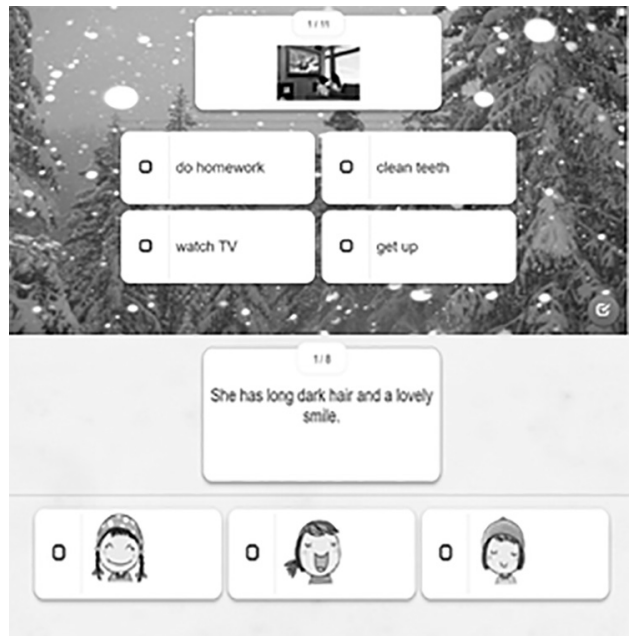

Рuc. 4. Фрагменти завдань

3 формування граматичної компетентності

3 метою розвитку навичок аудіювання в рамках теми «Parts of body. Appearance» дітям старшого дошкільного віку можна запропонувати скласти пазл, попередньо ознайомившись зі змістом відео-фрагменту «Daily routine» на відео-хостинзі YouTube. Доцільним буде також використання завдань на співставлення аудіо-фрагменту із малюнком (Рuc. 5).

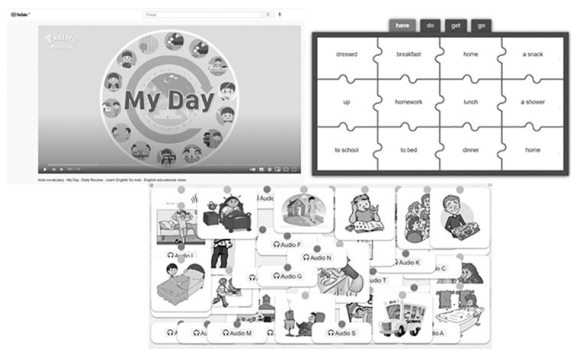

Puc. 5. Фрагменти завдань з аудіювання

Висновки. Отже, проаналізувавши можливості Web-сервісу LearningApps.org в формуванні іншомовної мовленнєвої діяльності дітей 6-7 років, можна зробити наступні висновки. Використання цікавих інтерактивних завдань, вправ та ігор на заняттях 3 англійської мови має ряд переваг, зокрема: підвищення мотивації дітей старшого дошкільного віку через різноманітність вибору завдань; поліпшення процесу запам'ятовування нових лексичних одиниць, або граматичного матеріалу; відпрацювання навичок швидкого перекладу слід з української на англійську та навпаки; активізує комунікативну діяльність дітей старшого дошкільного віку; сприяє принципам індивідуалізації навчання. Варто зазначити, що в цьому дослідженні ми надали лише загальну характеристику одного з багатьох існуючих Web-сервісів, який на нашу думку доцільно використовувати у процесі формування іншомовної мовленнєвої діяльності дітей 6-7 років. Порушена проблема потребує подальшого більш конкретного вивчення та розробки практичних рекомендацій для застосування інших популярних платформ та Web-сервісів у формуванні іншомовної мовленнєвої діяльності старших дошкільників.

\section{СПИСОК ВИКОРИСТАНОЇ ЛІТЕРАТУРИ}

1. Білусяк Б., Семаньків М. Використання Інтернет-Сервісів в навчальному процесі. Міжнар. наук.практ. конф. Інформаційні технології та комп’ютерне моделювання, Івано-Франківсь. 2018, 97-100. 2. Волобуева В. Использование сетевого сервера Learningapps.org в организации самостоятельной работы обучающихся неязыковых специальностей по английскому языку. Вестник Сургутского государственного педагогического университета. Сургут, 2017, № 5 (50), 39-47.

3. Мельник О. Технологіï Web 2.0 - інноваційний засіб навчання іноземної мови. Теорія і практика застосування ікт. Комп’ютер у школі та сім’ї. 2011, № 7, 17-21.

4. Петрик Л. Ефективність використання медіазасобів для вивчення іноземних мов у початковій школі: від усвідомлення до готовності. Освітологічний дискурс. 2019, 3-4 (26-27), 185-196. DOI: 10.28925/2312-5829.2019.3-4.185196. URL: https://www.researchgate.net/publication/337441035_The_ Effectiveness_of_Media_Use_to_Learn_Foreign_Languages_in_Primary_School_From_Awareness_to_R eadiness.

5. Gunter G., Campbell L., Braga J., Racilan M., V. Souza. Language learning apps or games: an investigation utilizing the RETAIN model. Rev. bras. linguist apl. 2016, Vol.16, No.2 Belo Horizonte Apr./June 2016, Epub Apr 05, 2016. DOI:10.1590/1984-639820168543.URL:http://www.scielo.br/scielo.php?script=sci_ arttext\&pid=S1984-63982016000200209\&lng=en\&tlng=en (дата звернення: 03.03.2021).

6. Kotenko O., Holovatenko T. Models of foreign language primary school teacher training in the EU. Innovative Scientific Researches: European Development Trends and Regional Aspect. Publishing House «Baltija Publishing», Riga (Latvia). 2020, 92-114. DOI: 10.30525/978-9934-588-38-9-5.

7. Learningapps.org. URL: https://learningapps.org/about.php (дата звернення: 03.03.2021).

8. Solomakha A., Kosharna N. Preparation of future teachers for using digital technologies in the process of early foreign language teaching. Освітологічний дискурс. 2020. (3(30)), 107-122. DOI: 10.28925/23125829.2020.3.8. URL: https://od.kubg.edu.ua/index.php/journal/article/view/739/605. 


\section{REFERENCES}

1. Bilusjak B., Semanjkiv M. Vykorystannja Internet-Servisiv v navchaljnomu procesi [Using of Internet Services in the educational process]. Mizhnar. nauk.-prakt. konf. Informacijni tekhnologhiji ta komp juterne modeljuvannja, Ivano-Frankivsj. 2018, 97-100.

2. Volobueva V. Ispol'zovanie setevogo servera Learningapps.org v organizacii samostojatel'noj raboty obuchajushhihsja nejazykovyh specialnostej po anglijskomu jazyku [Using Learningapps.org network server in the organization of independent work of students of non-linguistic specialties in English]. Vestnik Surgutskogo gosudarstvennogo pedagogicheskogo universiteta. Surgut, 2017, 5 (50), 39-47 (rus.)

3. Meljnyk O. Tekhnologhiji Web 2.0 - innovacijnyj zasib navchannja inozemnoji movy [Web 2.0 technologies are an innovative tool for learning a foreign language]. Teorija i praktyka zastosuvannja ikt. Komp'juter u shkoli ta sim'ji. 2011, 7, 17-21 (ukr.)

4. Petryk L. Efektyvnist' vykorystannya mediazosobiv dlya vyvchennya inozemnykh mov $\mathrm{u}$ pochatkoviy shkoli: vid usvidomlennya do hotovnosti [Efficiency of media tools use by primary school teacher at the foreign languages lessons: from awareness to readiness]. Osvitolohichnyy dyskurs. $\quad 2019, \quad 3-4 \quad$ (26-27), 185-196. DOI: 10.28925/2312-5829.2019.3-4.185196.URL: https://www.researchgate.net/publication/337441035_The_Effectiveness_of_Media_Use_to_Learn_ Foreign_Languages_in_Primary_School_From_Awareness_to_R eadiness (ukr).

5. Gunter G., Campbell L., Braga J., Racilan M., V. Souza Language learning apps or games: an investigation utilizing the RETAIN model. Rev. bras. linguist apl. 2016, Vol.16, No.2 Belo Horizonte. Apr./June 2016, Epub. Apr 05, 2016. DOI:10.1590/1984-639820168543.URL:http://www.scielo.br/scielo.php?script=sci_ arttext\&pid=S1984-63982016000200209\&lng=en\&tlng=en (дата звернення: 03.03.2021) (eng).

6. Kotenko O., Holovatenko T. Models of foreign language primary school teacher training in the EU. Innovative Scientific Researches: European Development Trends and Regional Aspect. Publishing House «Baltija Publishing», Riga (Latvia). 2020, 92-114. DOI: 10.30525/978-9934-588-38-9-5 (eng).

7. Learningapps.org. URL: https://learningapps.org/about.php (дата звернення: 03.03.2021) (eng).

8. Solomakha A., Kosharna N. Preparation of future teachers for using digital technologies in the process of early foreign language teaching. Освітологічний дискурс. 2020. (3(30)), 107-122. DOI: 10.28925/23125829.2020.3.8. URL: https://od.kubg.edu.ua/index.php/journal/article/view/739/605 (eng).

\section{Бровко Екатерина}

\section{ФОРМИРОВАНИЕ ИНОЯЗЫЧНОЙ РЕЧЕВОЙ ДЕЯТЕЛЬНОСТИ ДЕТЕЙ 6-7 ЛЕТ СРЕДСТВОМ WEB-CEPВИСA LEARNINGAPPS.ORG}

В статье рассмотрены потенциальные возможности и особенности использования Web-сервиса Learningapps.org в формировании иноязычной речевой деятельности детей 6-7 лет на занятиях по английскому языку. Осуществлена классификация видов упражнений по функциональному признаку (Multiple-choice, Sequence или Pairing, Order, Filling in, Group Puzzle, Crossword, Word grid, Patring Game and ect.). Подано их краткое описание. Проведен стратегический анализ Web-сервиса LearningApps.org в формировании иноязычной речевой деятельности детей 6-7 лет. Охарактеризован комплекс методических, дидактических, педагогических и психологических принципов, который реализуется в процессе использования Web-сервисов LearningApps.org на занятиях по английскому языку. Обозначены дидактические возможности формирования иноязычной речевой деятельности детей 6-7 лет на занятиях по английскому языку. Представлены фрагменты собственной разработки интерактивных упражнений в Webсервисе LearningApps.org направленых на изучение лексических единии, грамматических навыков, аудирование и закрепления изученного матиералу по теме «Parts of body. Appearance».

Ключевые слова: LearningApps.org; Web-сервис; английский язык; дети 6-7 лет; иноязычная речевая деятельность.

\section{Brovko Kateryna \\ FORMATION OF FOREIGN-LANGUAGE ACTIVITIES OF 6-7-YEAR-OLD CHILDREN USING THE WEB-SERVICE LEARNINGAPPS.ORG}

The study considers the potential opportunities and features of using the Web-service LearningApps.org in the formation of foreign-language activities of 6-7-year-old children in English classes. The classification of types of tasks on a functional basis (Multiple-choice, Sequence or Pairing, Order, Filling in, Group Puzzle, Crossword, Word grid, Patring Game and ect.) is carried out. A brief description is given. A strategic analysis of the Webservice LearningApps.org in the formation of foreign-language activities of 6-7-year-old children is presented. A set of methodological, didactic, pedagogical and psychological principles, which is implemented in the process 
of using Web-services LearningApps.org in English classes, is described. Didactic possibilities of formation foreign-language activities of 6-7-year-old children in English classes are considered. Among them: activation of children's vocabulary, formation reading skills and abilities, improvement of children's written speech, development of basic speech skills: listening, speaking, practicing children's use of grammatical forms, stimulation of children's word formation. Emphasis is placed on the effectiveness of using the Web-service LearningApps.org for the development of critical and creative thinking; formation of communication skills, in particular: analysis of material, comparison, comparison, establishment of associations; development of logic of sequence of actions and decisions, ability of systematization and generalization of material; teamwork skills in the process of solving problems. Fragments of own development of interactive exercises in the Web-service LearningApps.org aimed at studying lexical units, grammatical skills, listening and consolidation of the studied material by the topic «Parts of body. Appearance» are presented.

Key words: 6-7-year-old children; English; foreign-language activities; LearningApps.org; Web-service.

Стаття надійшла до редакції: 01.03.2021

Прийнято до друку: 10.03.2021 